\title{
Modest Evidence for Linkage and Possible Confirmation of Association Between NOTCH4 and Schizophrenia in a Large Veterans Affairs Cooperative Study Sample
}

\author{
A.D. Skol, ${ }^{1}$ K.A. Young, ${ }^{2}$ D.W. Tsuang, ${ }^{3}$ S.V. Faraone, ${ }^{4,5,6}$ S.L. Haverstock, ${ }^{7}$ S. Bingham, ${ }^{8}$ \\ S. Prabhudesai, ${ }^{9}$ F. Mena, ${ }^{10}$ A.S. Menon, ${ }^{11}$ Chang-En Yu, ${ }^{12}$ Paul Rudell, ${ }^{12}$ J. Pepple, ${ }^{4,6}$ F. Sauter, ${ }^{13}$ \\ C. Baldwin, ${ }^{14}$ D. Weiss, ${ }^{7}$ J. Collins, ${ }^{7}$ T. Keith, ${ }^{1}$ M. Boehnke, ${ }^{1}$ G.D. Schellenberg, ${ }^{12} *$ and M.T. Tsuang ${ }^{4,5,6}$ \\ ${ }^{1}$ Department of Biostatistics and Center for Statistical Genetics, University of Michigan, Ann Arbor, Michigan \\ ${ }^{2}$ Veterans Affairs Medical Center Waco, Texas \\ ${ }^{3}$ Veterans Affairs Puget Sound Health Care System, Mental Illness, Research, Education, and Clinical Center, \\ and Department of Psychiatry and Behavioral Sciences, University of Washington, Seattle, Washington \\ ${ }^{4}$ Brockton West Roxbury Veterans Affairs Medical Center, Brockton, Massachusetts, and Harvard Medical School \\ Department of Psychiatry at the Massachusetts Mental Health Center \\ ${ }^{5}$ Harvard Institute of Psychiatric Epidemiology and Genetics, Boston, Massachusetts \\ ${ }^{6}$ Department of Epidemiology, Harvard School of Public Health, Boston, Massachusetts \\ ${ }^{7}$ Veterans Affairs Medical Center, Augusta, Georgia \\ ${ }^{8}$ Cooperative Studies Program Coordinating Center, Veterans Affairs Medical Center, Perry Point, Maryland \\ ${ }^{9}$ Veterans Affairs Medical Center, Danville, Illinois \\ ${ }^{10}$ Veterans Affairs Medical Center, Tuskegee, Alabama \\ ${ }^{11}$ Veterans Affairs Medical Center, Perry Point, Maryland \\ ${ }^{12}$ Veterans Affairs Puget Sound Health Care System, Geriatric Research, Education, and Clinical Center, \\ and Departments of Gerontology and Geriatric Medicine, University of Washington, Seattle, Washington \\ ${ }^{13}$ Veterans Affairs Medical Center, New Orleans, Louisiana \\ ${ }^{14}$ Veterans Affairs Medical Center, Northport, New York
}

Wei and Hemmings [2000: Nat Genet 25:376377], using 80 British parent-offspring trios, identified a number of NOTCH4 variants and haplotypes that showed statistically significant evidence of association to schizophrenia. Specifically, the 10 repeat allele of a (CTG) $)_{n}$ marker and the 8 repeat allele of a (TAA) $n$ marker demonstrated excess transmission to affected individuals; $\mathrm{SNP2}^{1}$ and haplotypes SNP2-(CTG)n and SNP1 ${ }^{2}$-SNP2-

\footnotetext{
${ }^{1} \mathrm{SNP} 2$ is a $\mathrm{T} \rightarrow \mathrm{C}$ substitution resulting in an Msp1 site.

${ }^{2} \mathrm{SNP} 1$ is an $\mathrm{A} \rightarrow \mathrm{G}$ substitution resulting in an Msp1 site.
}

Grant sponsor: Department of Veterans Affairs Cooperative Study Program; Grant sponsor: Veterans Affairs Merit Review; Grant sponsor: VISN 20 Northwest Network Mental Illness, Research, Education, and Clinical Center.

*Correspondence to: Gerard D. Schellenberg, VAPSHCS, 182 GRECC, 1660 S. Columbian Way, Seattle, WA 98108; 206-7642701. E-mail: zachdad@u.washington.edu

Received 31 December 2001; Accepted 2 October 2002

DOI 10.1002/ajmg.b.10055
(CTG) $)_{n}$ also showed significant associations. In an attempt to replicate these findings, we tested for linkage and association between the same five markers used by Wei and Hemmings in 166 families collected from a multi-center study conducted by the Department of Veterans Affairs (DVA) Cooperative Study Program (CSP). The families include 392 affected subjects (schizophrenia or schizoaffective disorder, depressed) and 216 affected sibling pairs. The families represent a mix of European Americans $(\mathbf{n}=62,37 \%)$, African Americans $(\mathrm{n}=60,36 \%)$, and racially mixed or other races $(n=44,27 \%)$. We identified moderate evidence for linkage in the pooled race sample $(L O D=1.25)$ and found excess transmission of the $8(P=0.06)$ and $13(P=0.04)$ repeat alleles of the (TAA) ${ }_{n}$ marker to African American schizophrenic subjects. The 8 and 13 repeat alleles were previously identified to be positively associated with schizophrenia by Wei and Hemmings [2000: Nat Genet 25:376-377] and Sklar et al. [2001: Nat Genet 28:126-128], respectively.

๑) 2003 Wiley-Liss, Inc.

() 2003 Wiley-Liss, Inc. 
KEY WORDS: NOTCH4; chromosome 6; schizophrenia; association; linkage; genetics

\section{INTRODUCTION}

A number of positive linkage findings have been reported on chromosome $6 \mathrm{p}$, beginning with the identification by Straub et al. [1995] and Wang et al. [1995] of linkage to schizophrenia at 6p22-6p24. Many studies, based on samples of various ethnicities and using different diagnostic methods, have replicated these findings [Antonarakis et al., 1995; Moises et al., 1995; Schwab et al., 1995; Schizophrenia Linkage Collaborative Group (SLCG), 1996; Brzustowicz et al., 1997; Lindholm et al., 1999; Hwu et al., 2000]. Several groups have also reported linkage between schizophrenia and chromosome 6q [Cao et al., 1997; Kaufmann et al., 1998; Martinez et al., 1999; Schwab et al., 2000]. Nurnberger et al. [1999] and Daniels et al. [1997] offer helpful reviews of these earlier linkage findings. Nurnberger et al. [1999] also discusses some of the candidate genes within these regions that have been targets of association studies. Turecki et al. [1997] performed a metaanalysis of nine previous studies that reported linkage on chromosome $6 \mathrm{p}$. Unlike the majority of the studies above, which showed linkage peaks between $6 \mathrm{p} 22$ and $6 \mathrm{p} 24$, they found the strongest evidence for linkage at 6p21.3. Hwu et al. [2000], Schwab et al. [2000], and McGinnis et al. [2001] have since confirmed linkage in this region. The highest number of association studies have focused on this $6 \mathrm{p} 21.3$ region.

Several studies encouraged by the consistent positive linkage results on chromosome $6 \mathrm{p}$, sought to test for association between markers in candidate gene regions and schizophrenia. Wei and Hemmings [2000], using 80 British parent-offspring trios, scanned this region using the transmission disequilibrium test (TDT) [Spielman et al., 1994] on 13 markers within the MHC region (6p21.3). They found a marker in locus HSMHC3A5, known to contain the NOTCH4 gene, to be associated with schizophrenia. They proceeded to genotype four additional markers within NOTCH4: three in the $5^{\prime}$ flanking region, one in exon 1 , and another in intron 17, and conducted TDT tests on each marker as well as on several two and three marker haplotypes. The positions of these markers are shown in Figure 1. Wei and Hemmings [2000] found significant association results for markers (TAA) $)_{n}$ and $(\mathrm{CTG})_{\mathrm{n}}$ ( $P=0.00017$ and $P=0.000036$, respectively), while the marker haplotypes with the most significant associations were SNP2-(CTG) $)_{n}$ and SNP1-SNP2-(CTG) $(P=0.0000078$ and $P=0.000011$, respectively). An excess of the 10 copy allele of the $(\mathrm{CTG})_{\mathrm{n}}$ marker, $(\mathrm{CTG})_{10}$, and the 8 copy allele of the TAA marker, $(\mathrm{TAA})_{8}$, were found to be transmitted preferentially to schizophrenic offspring.

Sklar et al. [2000] tested all of the positive markers used by Wei and Hemmings [2000] for association using German Israeli, German, and Bulgarian family based samples, and a British case-control sample. They

\section{Marker \\ Position in \\ BAC Sequence}

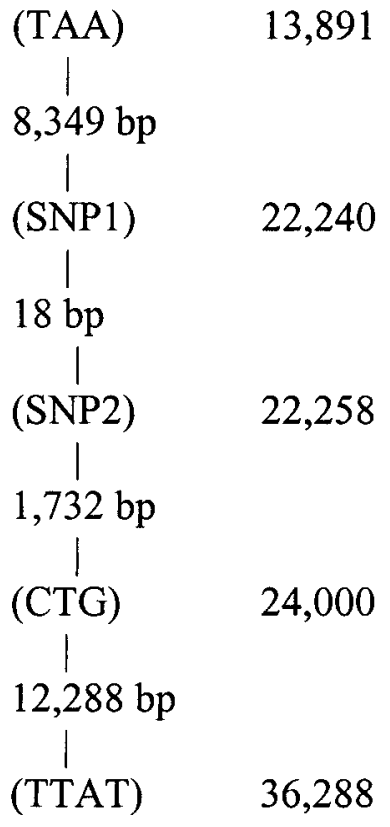

Fig. 1. Position of NOTCH4 markers on chromosome 6p21.3, genomic clone U89335. (Genbank [http:www.ncbi.nlm.nih.gov] GI: 1841541.) Genetic distances between markers indicated by the number of base pairs.

confirmed one previous finding of linkage to the NOTCH4 area in the German Israeli sib-pairs. Also, as reported in their Table I, but not noted in their text, they found that the 13 repeat allele of the (TAA) $n$ marker demonstrated excessive transmission to schizophrenics in the German Israeli sample $(P=0.018)$ and in their combined sample $(P=0.032)$. McGinnis et al. [2001], using 300 Scottish schizophrenics and 600 controls, tested for association using markers $(\mathrm{CTG})_{\mathrm{n}}$ and (TAA) ${ }_{\mathrm{n}}$, but found no strong evidence for association $(P=0.15$,

TABLE I. Number of Families and Affected Individuals Included in Each Analysis

\begin{tabular}{lccccc}
\hline & \multicolumn{2}{c}{ Narrow } & & \multicolumn{2}{c}{ Broad } \\
\cline { 2 - 3 } \cline { 5 - 6 } Race & $\begin{array}{c}\text { Number of } \\
\text { families }\end{array}$ & $\begin{array}{c}\text { Number } \\
\text { affected }\end{array}$ & & $\begin{array}{c}\text { Number of } \\
\text { families }\end{array}$ & $\begin{array}{c}\text { Number } \\
\text { affected }\end{array}$ \\
\hline AA & 44 & 101 & & 69 & 161 \\
EA & 52 & 109 & & 64 & 142
\end{tabular}

AA, African America; EA, European American. For the narrow ethnic group, both parents are of the same ethnic group (both either AA or EA). For the broad ethnic group categories, families with either one AA parent or twomixed race parents where each parent was part AA were added to the AA group; while families that had at least one EA parent and the second parent who was non-AA were added to the EA group. 
$P=0.16)$. Two Japanese case-control studies have also been performed, one using SNP1, SNP2, and (CTG) ${ }_{n}$ and the other using only (CTG) ; neither found evidence of association $\left(P=0.13\right.$ [at $(\mathrm{CTG})_{\mathrm{n}}$ ] and $P=0.71$, respectively) [Imai et al., 2001; Ujike et al., 2001]. Most recently, Fan et al. [2002] examined all five markers used by Wei and Hemmings [2000] using a Chinese sample of 544 cases and 621 controls and 300 trios. Their most significant result was from testing for different allele frequency distributions between cases and controls at the (TTAT) $)_{\mathrm{n}}$ marker $(P=0.03)$. The TDT for this marker yielded a $P$-value of 0.13 . Swift-Scanlan et al. [2002] examined the $(\mathrm{CTG})_{\mathrm{n}}$ marker in 65 multiplex bipolar pedigrees, postulating that there are shared genes involved in both schizophrenia and bipolar disorder. They found modest association between the $(\mathrm{CTG})_{13}$ allele and schizophrenia $(P=0.01)$. However, their result became less significant when they restricted their sample to a subset of 30 families that contained family members that exhibited psychotic symptoms $(P=0.10)$.

In this study, we assess evidence for linkage and association between schizophrenia and the five NOTCH4 markers used by Wei and Hemmings [2000] in 166 families collected through the Department of Veterans Affairs (DVA) Cooperative Study Program (CSP) [Tsuang et al., 2000]. We find suggestive evidence for linkage to schizophrenia to this region and, intriguingly, excess transmission of both $(\mathrm{TAA})_{8}$ and $(\mathrm{TAA})_{13}$ alleles to schizophrenics in our African American families-these are the same two alleles identified by Wei and Hemmings [2000] and Sklar et al. [2001], respectively. Unfortunately, this finding was not replicated in our European American families. Additionally, we were not able to replicate Wei and Hemmings [2000] positive association to $(\mathrm{CTG})_{\mathrm{n}}$, nor find association to any of the other three markers used in their study.

\section{MATERIALS AND METHODS}

The DVA CSP collected clinical data and blood samples from 166 families ascertained through a pair of schizophrenic siblings. A comprehensive description of the sample and methods of data collection has been published [Tsuang et al., 2000]. Family members were classified as affected if they had a diagnosis of schizophrenia or schizoaffective, depressed, based on the Diagnostic Interview for Genetic Studies (DIGS) [Nurnberger et al., 1994; Faraone et al., 1996]. This is the same classification scheme used by Wei and Hemmings [2000].

DSM-III-R diagnoses were made by two senior psychiatrists or psychologist investigators with clinical and research experience in the diagnosis of psychosis. The diagnosis was based on the content of the DIGS interview, information provided by relatives who had been interviewed with the Family Interview for Genetic Studies (FIGS), and a review of medical records [Tsuang et al., 2000, 2001; Faraone et al., 2002].

Among the 166 families, 124, 30, 7, 4, and 1 had two, three, four, five, and six affected members, respectively. There are a total of 216 affected sibling pairs in these families. The mean number of individuals sampled per family was 4.7. Most of the affected subjects $(\mathrm{n}=361 ; 92.1 \%)$ met DSM-III-R criteria for schizophrenia. The remainder $(\mathrm{n}=31)$ met criteria for schizoaffective disorder, depressed. A detailed description of the linkage analysis sample has been previously reported.

Genotypes were determined by PCR amplification of polymorphic loci using primers labeled with fluorescent probes [Tsuang et al., 2001]. PedCheck was used to identify genotypes incompatible with Mendelian inheritance [O'Connell and Weeks, 1998].

\section{Linkage and Linkage Disequilibrium Analysis}

We performed semi-parametric linkage analysis using the exponential model of Genehunter Plus [Kong and Cox, 1997], a modified version of Genehunter [Kruglyak et al., 1996], to confirm linkage to the NOTCH4 region in our sample. We used the $\mathrm{S}_{\text {pairs }}$ score that assesses identity by descent (IBD) sharing among all pairs of affected individuals within families.

We used two approaches to assess evidence of linkage disequilibrium between schizophrenia and any of the five NOTCH4 markers. The first is the pedigree disequilibrium test (PDT) which takes pedigrees and breaks them into mother-father-affected offspring trios and discordant sib pairs (DSP) [Martin et al., 2000]. For the trios, it calculates the difference between the number of transmissions and non-transmissions of an allele to the affected offspring. For DSP, the difference between allele frequency in the affected and unaffected sibs is calculated. For each pedigree, these two values are combined; all pedigree values are then summed and standardized, yielding a statistic that is asymptotically normally distributed and has power to detect deviations from the Mendelian transmission rates [Martin et al., 2001].

The second approach uses the family based association test (FBAT) [Rabinowitz and Laird, 2000]. In addition to being able to use extended families, the FBAT also handles missing data appropriately, and so does not waste information. Association between a specific allele and schizophrenia is assessed using a test statistic that sums a function of the number of alleles possessed by each affected individual over all individuals. The function of the number of alleles depends on the genetic model being considered. An empirical estimate of the variance is used, as recommended by $\mathrm{Xu}$ et al. [2001], to account for the fact that we are looking for association in the presence of linkage. Evidence for association to a given marker is determined by appropriately combining the allele specific test statistics.

In addition to the marker-disease associations, we also tested the four most significant haplotype-disease associations found by Wei and Hemmings [2000], namely (TAA) $)_{n}$-SNP1, SNP2-(CTG) $)_{n},(\text { TAA })_{n}-S N P 1-$ SNP2, and SNP1-SNP2-(CTG) $)_{\mathrm{n}}$ using both FBAT and PDT. We used Merlin [Abecasis et al., 2002] and Fugue [Abecasis et al., 2001] to infer the most likely haplotypes for each family.

Before performing the linkage or association analyses, we divided the families into racial groups based 
on the probands' parents' races as identified in the DIGS. For the narrow definition we included only those 122 families in which both parents are of the same racial group (both either African American, $n=60$, or European American, $n=62$ ). For the broad racial group categories, 31 families were added to the African American group. These families had either one African American parent or two-mixed race parents where each parent was part African American. Thirteen families were added to the European American group. These families had at least one European American parent and the second parent was non-African American.

We used 75 previously genotyped markers from four chromosomes to look for evidence of mispecified familial relationships. Of the 166 families, 30 had repeated genotype incompatibilities at many markers. For 14 families, reported pedigree structure was incorrect but could easily be corrected by use of the available genotype information [Boehnke and Cox, 1997]. Correct relationships for the remaining 16 families could not be resolved with our present data, and those families were excluded from the current analysis. We identified a single family with a genotyping error and excluded the data from the marker with the error for the entire family. Finally, seventeen additional families were excluded because they were missing enough genotype data that they provided no linkage information. Table I lists the races and number of families and affected individuals included in each analysis after exclusions.

We performed the linkage and PDT association tests on each racial group independently and again with all pedigrees combined. Since few observations per allele were available when running FBAT on a single race, we only obtained results for this test for all pedigrees combined.

\section{RESULTS}

Table II shows a summary of the linkage results using both definitions of race. We found suggestive evidence for linkage to the NOTCH4 region when using all families and the broad definition of race $(\mathrm{LOD}=1.25)$ and weaker evidence using the narrow definition $(\mathrm{LOD}=0.58)$. When considering African Americans alone, LOD scores of 0.81 and 0.65 were attained for the broad and narrow definitions of race, respectively. European Americans alone had LOD scores of 0.45 and 0.08 .

The results of a global test for association for each marker and haplotype using the PDT are summarized in Table III. None of the markers for either of the races reached statistical significance after correcting for

TABLE II. Linkage Results

\begin{tabular}{lcc}
\hline Race definition & Narrow & Broad \\
\hline AA & 0.65 & 0.81 \\
EA & 0.08 & 0.45 \\
Combined & 0.58 & 1.25 \\
\hline
\end{tabular}

Maximum LOD scores using narrow and broad race classifications as specified in Table I.
TABLE III. Global Test for Associations for Each Marker and Haplotype Using the Pedigree Disequilibrium Test (PDT), the Lowest $P$-Value is Reported (not Corrected for Multiple Comparisons)

\begin{tabular}{|c|c|c|c|}
\hline Race & AA & EA & Combined \\
\hline$(\mathrm{TAA})_{\mathrm{n}}$ & 0.04 & 0.38 & 0.29 \\
\hline SNP1 & 0.49 & 0.82 & 0.51 \\
\hline SNP2 & 0.22 & 0.43 & 0.89 \\
\hline$(\mathrm{CTG})_{\mathrm{n}}$ & 0.76 & 0.23 & 0.93 \\
\hline$(\mathrm{TTAT})_{\mathrm{n}}$ & 0.32 & 0.64 & 0.27 \\
\hline$(\mathrm{TAA})_{\mathrm{n}}-\mathrm{SNP} 1$ & 0.57 & 0.41 & 0.88 \\
\hline$(\mathrm{TAA})_{\mathrm{n}}-\mathrm{SNP} 1-\mathrm{SNP} 2$ & 0.32 & 0.60 & 0.72 \\
\hline SNP1-SNP2-(CTG $)_{n}$ & 0.19 & 0.68 & 0.38 \\
\hline SNP2-(CTG $)_{n}$ & 0.18 & 0.78 & 0.33 \\
\hline
\end{tabular}

$P$-values are based on the sumPDT statistic.

multiple tests, although (TAA) $)_{n}$ was nominally significant at the 0.05 level for African Americans. The 8 and 13 repeat alleles of this marker were found more often in schizophrenic sibs than unaffected siblings $(P=0.06$, $P=0.04$ ), while the 12 repeat allele was more frequently found in unaffected siblings $(P=0.03)$. Interestingly, the 8 repeat allele was found to be the most significant excessively transmitted allele by Wei and Hemmings [2000] $(P=0.0002)$, while Sklar et al. [2001] found the 13 copy allele to be the allele most excessively transmitted to affecteds $(P=0.032)$. These transmission differences were not observed in the European Americans in our sample. Tables IV and V show the allele frequency distribution and the number of transmissions and nontransmissions of alleles from heterozygous parents to affected offspring for our EA, AA, and combined sample, for Wei and Hemmings [2000] sample and for the Sklar et al. [2001] sample.

Table VI summarizes the results of the tests for association using the FBAT. The most significant result was in marker (TTAT) $)_{n}$ using the recessive model. The multi-allelic test for the marker produced a $P$-value of 0.10 , which was driven by an excess transmission of the most common allele to affected individuals $(P=0.05)$.

Although the association result for (TAA) $n$ was significant at the 0.05 level, it does not remain significant after correcting for the multiple tests performed. An appropriate significance level is difficult to determine since most of the tests that were performed are dependent and so a Bonferonni adjustment would be overly conservative. However, given that well over 100 tests were performed and that tests at each marker are close to being independent, it is likely that the appropriate significance threshold is at least an order of magnitude less than 0.05 . It is, however, also appropriate to note that we are conducting a follow-up investigation and that the (TAA) ${ }_{n}$ alleles that we found to be most significantly associated with schizophrenia are the same as those previously identified by Wei and Hemmings [2000] and Sklar et al. [2001]. The interpretation is further complicated since our positive results do not extend to our European American sample. 
TABLE IV. Allele Transmission in Trios and Discordant Sib Pairs (DSP) for Marker (TAA)

\begin{tabular}{|c|c|c|c|c|c|c|}
\hline Allele & & VA combined & VA AA & VA EA & Wei and Hemmings & Sklar et al. \\
\hline \multirow[t]{2}{*}{7} & $\mathrm{~T}: \mathrm{N}$ & $0: 2$ & $0: 2$ & $0: 0$ & $1: 1$ & $17: 8$ \\
\hline & Aff:Unaff & $5: 7$ & $2: 3$ & $3: 4$ & & \\
\hline \multirow[t]{2}{*}{8} & $\mathrm{~T}: \mathrm{N}$ & $20: 26$ & $6: 2$ & $14: 14$ & $53: 21$ & $152: 150$ \\
\hline & Aff:Unaff & $90: 77$ & $11: 5$ & $79: 72$ & & \\
\hline \multirow[t]{2}{*}{9} & T:N & $27: 27$ & $19: 17$ & $8: 10$ & $22: 35$ & 139:139 \\
\hline & Aff:Unaff & $87: 78$ & $35: 33$ & $52: 43$ & & \\
\hline \multirow[t]{2}{*}{10} & T:N & $8: 6$ & $4: 4$ & $4: 2$ & $22: 32$ & $120: 139$ \\
\hline & Aff:Unaff & 68:52 & $28: 20$ & $8: 7$ & & \\
\hline \multirow[t]{2}{*}{11} & T:N & $2: 7$ & $0: 6$ & $2: 1$ & $5: 7$ & $11: 15$ \\
\hline & Aff:Unaff & $19: 21$ & $11: 14$ & $8: 7$ & & \\
\hline \multirow[t]{2}{*}{12} & $\mathrm{~T}: \mathrm{N}$ & $2: 4$ & $0: 2$ & $2: 2$ & $7: 13$ & $19: 27$ \\
\hline & Aff:Unaff & $19: 17$ & $11: 12$ & $8: 5$ & & \\
\hline \multirow[t]{2}{*}{13} & $\mathrm{~T}: \mathrm{N}$ & $4: 1$ & $2: 0$ & $2: 1$ & $5: 4$ & $32: 17$ \\
\hline & Aff:Unaff & $28: 19$ & $21: 11$ & $7: 8$ & & \\
\hline \multirow[t]{2}{*}{14} & $\mathrm{~T}: \mathrm{N}$ & $5: 5$ & $5: 3$ & $0: 2$ & $4: 6$ & $41: 32$ \\
\hline & Aff:Unaff & $12: 15$ & $7: 6$ & $5: 9$ & & \\
\hline \multirow[t]{2}{*}{15} & T:N & $0: 0$ & $0: 0$ & $0: 0$ & $0: 0$ & $2: 5$ \\
\hline & Aff:Unaff & $0: 0$ & $0: 0$ & $0: 0$ & & \\
\hline
\end{tabular}

T:N are the numbers of transmissions and non-transmissions of the allele from heterozygous parent to affected offspring, respectively. Aff:Unaff are the numbers of alleles possessed by affected and unaffected members of a discordant sib pair, respectively.

We repeated our association analysis again using a more restrictive definition of schizophrenia by reassigning 21 subjects diagnosed as schizoaffective disorder, depressed (SZD) (11 AA and $10 \mathrm{EA})$ to the unaffected group. The results from linkage analysis and tests of association using FBAT changed only nominally. Marker (TAA) $n$ was found to have the strongest association to schizophrenia when using FBAT and the narrower definition of schizophrenia $(P=0.14)$. The results from the PDT also changed very little. Recall that when using the broader definition of schizophrenia, association to (TAA) $n$ marker was found to be nominally significant in the AA sample $(P=0.04)$. Although the strength of this association decreased slightly $(P=0.06)$, the evidence for association between the 8 repeat allele and schizophrenia weakened substantially $(P=0.27$ [SZD excluded], $P=0.06$ [SZD included]). The evidence for association to the 13 repeat allele did not change significantly. The largest increase in evidence for association was observed for marker $(\mathrm{CTG})_{\mathrm{n}}(P=0.08$ [SZD excluded], $P=0.23$ [SZD included]). The significance at this marker is driven by the (CTG) ${ }_{11}$ allele being transmitted to affected individuals twice as often as to unaffected $(P=0.02)$. An association with this allele was previously reported in the German Israeli sib pair sample of Sklar et al. [2001] $(P=0.003)$ and by SwiftScanlan et al. [2002] using a sample of subjects with psychotic symptoms and broadly defined bipolar illness $(P=0.05)$. However, in both of these samples this allele was transmitted more often to the unaffected sibs.

\section{DISCUSSION}

Using our Veteran's Affair Cooperative Study sample [Tsuang et al., 2000], we found moderate evidence for linkage of schizophrenia to the NOTCH4 region using the combined race sample, a broad definition of race and an affection status including schizoaffective, depressed, and schizophrenia (LOD $=1.25)$. This result is consistent with a number of previous studies [Turecki et al., 1997; Hwu et al., 2000; Schwab et al., 2000; McGinnis et al., 2001]. Our most significant association result was for marker $(\mathrm{TAA})_{\mathrm{n}}(P=0.04)$, which, due to the large number of tests performed and previously significant findings by Wei and Hemmings [2000] and Sklar et al. must be interpreted with caution. The two most significant alleles in the African American families were $(\mathrm{TAA})_{8}$ and $(\mathrm{TAA})_{13}$ which were transmitted more frequently to affected than unaffected individuals $(P=0.06, P=0.04)$. The excessive transmission of the 8 repeat allele is consistent with Wei and Hemmings [2000] results and the excess transmission of the 13 copy allele was also found by Sklar et al. [2001]. However, these results were not replicated in our European American sample, which is more racially similar to both the Sklar et al. [2001] and Wei and Hemmings [2000] samples. It is unclear how to reconcile this discrepancy, although racial heterogeneity, gene-environment interaction, and/or admixture may contribute to the difference. An unknown epistatic locus may exist in the AA sample that modifies the effect of the 8 and 13

TABLE V. Allele Frequency Distribution in Samples Showing Evidence of Association

\begin{tabular}{lccccccccc}
\hline Sample/allele & 7 & 8 & 9 & 10 & 11 & 12 & 13 & 0.035 & 0.007 \\
VA (EA) & 0.028 & 0.400 & 0.263 & 0.172 & 0.014 & 0.042 & 0.039 & 0.14 \\
VA (AA) & 0.063 & 0.138 & 0.188 & 0.193 & 0.084 & 0.079 & 0.111 & 0.128 & 0.017 \\
VA (combined) & 0.044 & 0.290 & 0.229 & 0.181 & 0.044 & 0.058 & 0.067 & 0.077 & 0.010 \\
Wei and Hemming & 0.084 & 0.311 & 0.240 & 0.227 & 0.050 & 0.084 & 0.038 & 0.042 \\
Sklar et al. & 0.017 & 0.364 & 0.287 & 0.176 & 0.002 & 0.039 & 0.043 & 0.067 & 0.006 \\
\hline
\end{tabular}


TABLE VI. Tests for Association Using the Family Based Association Test, the $P$-Value for Each Marker and Haplotype is Reported

\begin{tabular}{lccc}
\hline Model & Additive & Recessive & Dominant \\
\hline (TAA) & 0.21 & 0.89 & 0.34 \\
SNP1 & 0.29 & 0.57 & 0.57 \\
SNP2 & 0.67 & 0.73 & 0.73 \\
(CTG) & 0.85 & 0.56 & 0.93 \\
(TTAT) & 0.40 & 0.10 & 0.47 \\
(TAA)n-SNP1 & 0.47 & 0.65 & 0.56 \\
(TAA)n-SNP1-SNP2 & 0.46 & 0.73 & 0.58 \\
SNP1-SNP2-(CTG) & 0.21 & a & 0.35 \\
SNP2-(CTG) & 0.40 & a & 0.45 \\
\hline
\end{tabular}

aToo few observations of recessive genotypes to perform calculation. A minimum of ten informative families was necessary to compute the test statistic. The empirical variance was used to calculate the test statistic (recommended by Lake et al., 2001 when testing in an area of linkage).

repeat alleles, increasing the prevalence of schizophrenia in individuals inheriting these alleles. Ethnic admixture in our EA sample may have influenced our ability to detect association in that sample. Unfortunately, we do not have sufficiently detailed racial information to determine which EA individuals are of British descent.

We also tested for association between schizophrenia and the four haplotypes Wei and Hemmings [2000] found to be most strongly association with schizophrenia. We found no association between these haplotypes and schizophrenia. Although haplotypes were not able to be determined unambiguously, the most likely haplotypes were able to be inferred using Merlin and Fugue. The use of inferred haplotypes in our analysis could have adversely affected our ability to find an association, however, this is not likely given the small number and density of markers used.

We repeated the association and linkage analyses by restricting the assignment of schizophrenia only to those individuals diagnosed with schizophrenia. The significance of the association between (TAA) 8 and (TAA) 13 and schizophrenia decreased from $P$-values of 0.06 and 0.04 to 0.23 and 0.06 , respectively. Aside from these changes and the increase in the evidence for association between the marker (CTG) $)_{n}$ and allele $(\mathrm{CTG})_{11}$ and schizophrenia in the our EA sample, no other associations or linkage changed significantly.

Six previous studies have attempted to replicate Wei and Hemmings [2000] finding, two of which had samples that were ethnically similar to the original British sample. Neither McGinnis et al. [2001] Scottish sample nor Sklar et al. [2001] British case-control sample demonstrated significant association between NOTCH4 markers and schizophrenia. Both of these studies had sufficient sample sizes to detect gene effects of the magnitude suggested by Wei and Hemmings [2000] findings. Sklar et al. [2001] were also unable to find evidence for association using German and Bulgarian trios or German Israeli sib pairs.

Several possibilities could be considered to explain the discrepancy between Wei and Hemmings [2000] results and those of previous studies and our own. First, the variation in the assessment and or definition of the affected phenotype might explain the differences in the significance of association. Second, as suggested by McGinnis et al. [2001], it is possible that Wei and Hemmings [2000] sample contains a polymorphism in a susceptibility gene that is significantly more common in the Welsh. Third, it is possible that Wei and Hemmings [2000] positive findings, although highly significant, represent a false positive.

We recognize that our sample is less than ideal for an association study. We have only 21 families with fully genotyped trios, and although we have a total of 292 DSP, the low penetrance of schizophrenia results in overmatching of affected and unaffected siblings. These characteristics of our families and schizophrenia may have limited our power to detect associations [Boehnke and Langefeld, 1998]. Additionally, racial heterogeneity is present, so even though linkage was strongest using the combined race sample, susceptibility variants may be different, or at different frequencies in the two races. Hence, our failure to detect an association in the European American sample may represent a false negative.

In conclusion, our study presents intriguing evidence that an association may exist between schizophrenia and the (TAA) $)_{n}$ locus of NOTCH4. However, it remains possible that other known genes in this region, such as PBX2, AGPAT1, AGER, and TNXA, are responsible for the suggestive linkage results. Associations between these genes and schizophrenia should be explored in future studies.

\section{ACKNOWLEDGMENTS}

This work was supported by funds from the DVA CSP (Ming T. Tsuang, Study Chairman), a Veterans Affairs Merit Review (Gerard Schellenberg, PI), and VISN 20 Northwest Network Mental Illness, Research, Education, and Clinical Center (Murray Raskind, PI). We are indebted to the VA Cooperative Studies Program Office (Daniel Deykin, M.D., John R. Feussner, M.D., Janet Gold, and Ping Huang, Ph.D.) for their support of this study, to the Planning Committee (Stephen V. Faraone, Ph.D., Steven Hartman, M.D., Paul Hsu, Ph.D., Jurg Ott, Ph.D., Carlos Pato, M.D., Sarita Prabhudesai, M.D., Bernd Seizinger, M.D., Ph.D., Ming T. Tsuang, MD, Ph.D., and David G. Weiss, Ph.D.) for their early guidance and direction, to the Data Monitoring Committee (Raymond R. Crowe, M.D., L. ErlenmeyerKimling, Ph.D., T. Conrad Gilliam, Ph.D., Sarnoff Mednick, Ph.D., Neil Risch, Ph.D., and George Winokur, M.D. [deceased]) for their careful oversight throughout the project and to the Perry Point Coordinating Center Human Rights Committee (Clint McSherry, Edgard Perez, Maurice Moore, Adele Gilpin, Judith Rubin, Thomas Hobbins, David Highfield, Joseph Libonati, Scott Jones, Megan Arthurs, Lawrence Appel) for their oversight of human subjects issues. This study represents the collaborative efforts of Investigators and personnel from the Chairman's office at the Brockton/ West Roxbury VA, Brockton, MA, the Cooperative Studies Program Coordinating Center at the Perry Point VA, Perry Point, MD, and the seven VA Medical 
Center data collection sites: Danville, IL and Northport, NY (Phase I), and Augusta, GA, Perry Point, MD, New Orleans, LA, Tuskegee, AL, and Waco, TX (Phase II). Study Participants include Investigators: Ming T. Tsuang, M.D., Ph.D., Chairman, Charlene Baldwin, M.D., Stephen Bingham, Ph.D., Joseph Collins, Sc.D., Thomas Craig, Ph.D., Lynn DeLisi, M.D., Stephen Faraone, Ph.D., Lawrence B. Greenberg, M.D., Susan Haverstock, M.D., Janet Johnson, M.D., Felicitas Mena, M.D., Kumar Menon, M.D., Ramanujam Mohan, M.D., John Pepple, Ph.D., Sarita Prabhudesai, M.D., Fred Sautter, Ph.D., David Weiss, Ph.D., and Paul Hicks, MD., Ph.D.; the Study Coordinator, Lisa Gabel; Research Assistants: Rita Bily, M.S.N., Alicia Borges, Denise Brady-Elliott, M.S., Paula Cerveny, B.S.N., Lisa Crawford, M.S., Pamela Farrow Hampton, Hilda Hays, R.N., Patricia Hill, M.Ed., Barbara Kovac, R.N., Marilyn Krabbe, M.S., Monica Landi, M.S.W., Joel Maple, M.Ed., Dwight Martin, Linda Myrick, R.N., Susan Old, M.S., Charlene Poche, Mary Jo Reik, M.S.W., Rhonda Reynolds, R.N., Jacqueline Rose, M.S., and Valerie Wright, M.A. and Lab Research Assistant at Genome Therapeutics Corporation: Neva J. Capparell; consultants: Tim Keith, Ph.D. and Jurg Ott, Ph.D.; the staff of the Chairman's Office: Deborah Catt and Karen Irwin; staff at the Cooperative Studies Program Coordinating Center at the Perry Point VAMC: Colleen Crigler, Patricia Grubb, Anne Horney, M.S., Sandra Kilby, Ruth Ortiz, Maxine Rhoads, Elizabeth Spence, and Annette Wiseman; and staff at the VA Puget Sound Health Care System, Seattle Division: Darren Bisset, Leslie Leong, Leo-Jean Anderson, Charisma Eugenio, and Elaine Loomis for technical assistance.

\section{REFERENCES}

Abecasis GR, Martin ER, Lewitzky S. 2001. Estimation of haplotype frequencies from diploid data. Am J Hum Genet 69:S198.

Abecasis GR, Cherny SS, Cookson WO, Cardon LR. 2002. Merlin-rapid analysis of dense genetic maps using sparse gene flow trees. Nat Genet 30:97-101.

Antonarakis SE, Blouin J, Pulver AE, Wolyniec P, Lasseter VK, Nestadt G, Kasch L, Babb R, Kazazian HH, Dombroski B, Kimberland M, Ott J, Housman D, Karayiorgou M, MacLean CJ. 1995. Schizophrenia susceptibility and chromosome 6p24-22. Nat Genet 11:235-236.

Boehnke M, Cox NJ. 1997. Accurate inference of relationships in sib-pair linkage studies. Am J Hum Genet 61:423-429.

Boehnke M, Langefeld CD. 1998. Genetic association mapping based on discordant sib pairs: The discordant-alleles test. Am J Hum Genet 62:950-961.

Brzustowicz LM, Honer WG, Chow EWC, Hogan J, Hodgkinson K, Bassett AS. 1997. Use of a quantitative trait to map a locus associated with severity of positive symptoms in familial schizophrenia to chromosome 6p. Am J Hum Genet 61:1388-1396.

Cao Q, Martinez M, Zhang J, Sanders AR, Badner JA, Cravchik A Markey CJ, Beshah E, Guroff JJ, Maxwell ME, Kazuba DM, Whiten R, Goldin LR, Gershon ES, Gejman PV. 1997. Suggestive evidence for a schizophrenia susceptibility locus on chromosome $6 q$ and a confirmation in an independent series of pedigrees. Genomics 43:1-8.

Daniels JK, Spurlock G, Williams NM, Cardno AG, Jones LA, Murphy KC, Asherson P, Holmans P, Fenton I, McGuffin P, Owen MJ. 1997. Linkage study of chromosome $6 \mathrm{p}$ in sib-pairs with schizophrenia. Am J Med Genet 74:319-323.

Fan JB, Tang JX, Gu NF, Feng GY, Zou FG, Xing YL, Shi JG, Zhao SM, Zhu SM, Ji LP, Sun WW, Zheng YL, Liu WQ, Breen G, St. Clair D, He L. 2002. A family-based and case-control association study of the NOTCH4 gene and schizophrenia. Mol Psychiatry 7:100-103.
Faraone SV, Blehar M, Pepple J, Moldin SO, Norton J, Nurnberger JI, Malaspina D, Kaufmann CA, Reich T, Cloninger CR, DePaulo JR, Berg K, Gershon ES, Kirch DG, Tsuang MT. 1996. Diagnostic accuracy and confusability analyses: An application to the diagnostic interview for genetic studies. Psychol Med 26:401-410.

Faraone SV, Skol AD, Tsuang DW, Bingham S, Young KA, Prabhudesai S, Haverstock SL, Mena F, Menon AS, Bisset D, Pepple J, Sautter F, Baldwin C, Weiss D, Collins J, Keith T, Boehnke M, Tsuang MT, Schellenberg GD. 2002. Linkage of chromosome 13q32 to schizophrenia in a large veterans affairs cooperative study sample. Am J Med Genet 114:598-604.

Hwu HG, Lin M-W, Lee P-C, Lee SF, Ou-Yang W-C, Liu C-M. 2000. Evaluation of linkage of markers on chromosome $6 \mathrm{p}$ with schizophrenia in Taiwanese families. Am J Med Genet 96:74-78.

Imai K, Harada S, Kawanishi Y, Tachikawa H, Okubo T, Suzuki T. 2001. The (CTG)n polymorphism in the NOTCH4 gene is not associated with schizophrenia in Japanese individuals. BioMedcentral Psychiatry $1: 1-4$.

Kaufmann CA, Suarez B, Malaspina D, Pepple J, Svrakic D, Market P, Meyer J, Zambuto CT, Schmitt K, Matise TC, Friedman JMH, Hample C, Lee H, Shore D, Wynne D, Faraone SV, Tsuang MT, Cloninger CR. 1998. NIMH genetics initiative millennium schizophrenia consortium: Linkage analysis of African-American pedigrees. Am J Med Genet 81:282-289.

Kong A, Cox NJ. 1997. Allele-sharing models: LOD scores and accurate linkage tests. Am J Hum Genet 61:1179-1188.

Kruglyak L, Daly MJ, Reeve-Daly MP, Lander ES. 1996. Parametric and nonparametric linkage analysis: A unified multipoint approach. Am J Hum Genet 58:1347-1363.

Lake S, Blacker D, Laird N. 2001. Family based tests in the presence of association. Am J Hum Genet 67:1515-1525.

Lindholm E, Ekholm B, Balciuniene J, Johansson G, Castensson A, Koisti M, Nylander P-O, Pettersson U, Adolfsson R, Jazin E. 1999. Linkage analysis of a large Swedish kindred provides further support for a susceptibility locus for schizophrenia on chromosome 6p23. Am J Med Genet 88:369-377.

Martin ER, Monks SA, Warren LL, Kaplan NL. 2000. A test for linkage and association in general pedigrees: The pedigree disequilibrium test. Am J Hum Genet 67:146-154.

Martin ER, Bass MP, Kaplan NL. 2001. Correcting for a potential bias in the pedigree disequilibrium test. Am J Hum Genet 68:1065-1067.

Martinez M, Goldin LR, Cao Q, Zhang J, Sanders AR, Nancarrow DJ, Taylor JM, Levinson DF, Kirby A, Crowe RR, Andreasen NC, Black DW, Silverman JM, Lennon DP, Nertney DA, Brown DM, Mowry BJ, Gershon ES, Gejman PV. 1999. Follow-up study on a susceptibility locus for schizophrenia on chromosome 6q. Am J Med Genet 88:337343

McGinnis RE, Fox H, Yates P, Cameron L, Barnes MR, Gray IC, Spurr NK, Jurko O, St. Clair D. 2001. Failure to confirm NOTCH4 association with schizophrenia in a large population-based sample from Scotland. Nat Genet 28:128-129.

Moises HW, Yang L, Kristbjarnarson H, Wiese C, Byerley W, Macciardi F, Arolt V, Blackwood D, Liu X, Sjogren B. 1995. An international two-stage genome-wide search for schizophrenia susceptibility genes. Nat Genet 11:321-324.

Nurnberger JI, Blehar MC, Kaufmann CA, York-Cooler C, Simpson SG, Harkavy-Friedman J, Severe JB, Malaspina D, Reich T. 1994. Diagnostic interview for genetic studies. Rationale, unique features, and training. NIMH genetics initiative. Arch Gen Psychiatry 51:849859; discussion 863-864

Nurnberger JI Jr, Foroud T, Eckstein G, Ekelund J, Faraone S, Goldman D, Hinrichs T, Hwu HG, Kelsoe J, Owen M. 1999. Chromosome 6 workshop report. Am J Med Genet 88:233-238.

O'Connell JR, Weeks DE. 1998. PedCheck: A program for identification of genotype incompatibilities in linkage analysis. Am J Hum Genet 63:259-266.

Rabinowitz D, Laird N. 2000. A unified approach to adjusting association tests for population admixture with arbitrary pedigree structure and arbitrary missing marker information. Hum Hered 50:211-223.

Schwab SG, Albus M, Hallmayer J, Honig S, Borrmann M, Lichtermann D, Ebstein RP, Achenheil M, Lerer B, Risch N, Maier W, Wildenauer DB. 1995. Evaluation of a susceptibility gene for schizophrenia on chromosome $6 \mathrm{p}$ by multipoint affected sib-pair linkage analysis. Nat Genet $11: 325-327$. 
Schwab SG, Hallmayer J, Albus M, Eckstein GN, Borrmann M, Segman RH, Hanses C, Freymann J, Yakir A, Trixler M, Falkai P, Rietschel M, Maier W, Wildenauer DB. 2000. A genome-wide autosomal screen for schizophrenia susceptibility loci in 71 families with affected siblings: Support for loci on chromosome 10p and 6. Mol Psychiatry 5:638649

Sklar P, Schwab SG, Williams NM, Daly M, Schaffner S, Maier W, Albus M, Trixler M, Eichhammer P, Lerer B, Hallmayer J, Norton N, Williams H, Zammit S, Cardno AG, Jones S, McCarthy G, Milanova V, Kirov G, O’Donovan MC, Lander ES, Owens MJ, Wildenauer DB. 2001. Association analysis of NOTCH4 loci in schizophrenia using family and population-based controls. Nat Genet 28:126-128.

Schizophrenia Linkage Collaborative Group (SLCG). 1996. Additional support for schizophrenia linkage on chromosome 6 and 8: A multicenter study. Am J Med Genet 67:580-594.

Spielman RS, McGinnis RE, Ewens WJ. 1994. The transmission/disequilibrium test detects cosegregation and linkage. Am J Hum Genet 54:559560.

Straub RE, MacLean CJ, O’Neill FA, Burke J, Murphy B, Duke F, Shinkwin R, Webb BT, Zhang J, Walsh D, Kendler KS. 1995. A potential vulnerability locus for schizophrenia on chromosome 6p24-22: Evidence for genetic heterogeneity. Nat Genet 11:287-292.

Swift-Scanlan T, Lan TH, Fallin MD, Coughlin JM, Potash JB, DePaulo JR, McInnis MG. 2002. Genetic analysis of the (CTG)n NOTCH4 polymorphism in 65 multiplex bipolar pedigrees. Psychiatr Genet 12: 43-47.
Tsuang MT, Faraone SV, Bingham S, Young K, Prabhudesai S, Haverstock SL, Mena F, Menon AS, Pepple J, Johnson J, Baldwin C, Weiss D, Collins J. 2000. Department of Veterans Affairs Cooperative Studies Program genetic linkage study of schizophrenia: Ascertainment methods and sample description. Am J Med Genet 96:342-347.

Tsuang DW, Skol AD, Faraone SV, Bingham S, Young KA, Prabhudesai S, Haverstock SL, Mena F, Menon AS, Bisset D, Pepple J, Sauter F, Baldwin C, Weiss D, Collins J, Boehnke M, Schellenberg GD, Tsuang MT. 2001. Examination of genetic linkage of chromosome 15 to schizophrenia in a large Veterans Affairs Cooperative Study sample. Am J Med Genet 105:662-668.

Turecki G, Rouleau GA, Joober R, Mari J, Morgan K. 1997. Schizophrenia and chromosome 6p. Am J Med Genet 74:195-198.

Ujike H, Takehisa Y, Takaki M, Tanaka Y, Nakata K, Takeda T, Kodama M, Fujiwara Y, Yamamoto A, Kuroda S. 2001. NOTCH4 gene polymorphism and susceptibility to schizophrenia and schizoaffective disorder. Neurosci Lett 301:41-44.

Wang S, Sun CS, Walczak CA, Ziegle JS, Kipps BR, Goldin LR, Diehl SR 1995. Evidence for a susceptibility locus for schizophrenia on chromosome 6pther-p22. Nat Genet 10:41-46.

Wei J, Hemmings GP. 2000. The NOTCH4 locus is associated with susceptibility to schizophrenia. Nat Genet 25:376-377.

Xu X, Horvath S, Laird N. 2001. The FBAT (family based association test) program: Testing for linkage and association with family data http:// www.biostat.harvard.edu/ fbat/fbatdoc.htm. 